\title{
Cervical cancer screening in primary health care setting in Sudan: a comparative study of visual inspection with acetic acid and Pap smear
}

This article was published in the following Dove Press journal:

International Journal of Women's Health

24 February 2012

Number of times this article has been viewed

\author{
Ahmed Ibrahim' \\ Arja R Aro' \\ Vibeke Rasch ${ }^{2}$ \\ Eero Pukkala ${ }^{3,4}$ \\ 'Unit for Health Promotion Research, \\ University of Southern Denmark, \\ Esbjerg, Denmark; ${ }^{2}$ Department of \\ Obstetrics and Gynecology, Odense \\ University Hospital, Odense, Denmark; \\ ${ }^{3}$ Finnish Cancer Registry, Institute for \\ Statistical and Epidemiological Cancer \\ Research, Helsinki, Finland; ${ }^{4}$ School of \\ Public Health, University of Tampere, \\ Tampere, Finland
}

Objective: To determine the feasibility of visual inspection with the use of acetic acid (VIA) as a screening method for cervical cancer, an alternative to the Pap smear used in primary health care setting in Sudan, and to compare sensitivity, specificity, positive and negative predictive values, and histological diagnosis of positive cases of both tests.

Methods: A cross-sectional study of 934 asymptomatic women living in Khartoum, Sudan, was conducted during 2009-2010. A semi-structured questionnaire containing socio-economic and reproductive variables was used to collect data from each participant. Methods of screening used were VIA and conventional Pap smear, followed by colposcopy and biopsy for confirmation of the positive results of both screening tests.

Results: The tests identified altogether $119(12.7 \%)$ positive women. VIA detected significantly more positive women than Pap smear (7.6\% versus 5.1\%; $P=0.004)$, with an overlap between the two screening tests in $19 \%$ of positive results. There was no significant difference between VIA and Pap smear findings and sociodemographic and reproductive factors among screened women. Use of colposcopy and biopsy for positive women confirmed that 88/119 (73.9\%) were positive for cervical intraepithelial neoplasia. VIA had higher sensitivity than Pap smear (74.2\% versus $72.9 \% ; P=0.05)$ respectively. Out of 88 confirmed positive cases, $22(25.0 \%)$ cases were invasive cervical cancer in stage 1 , of which 19 versus three were detected by VIA and Pap smear respectively $(P=0.001)$. VIA had higher sensitivity and lower specificity than Pap smear $(60.2 \%$ versus $47.7 \%)$ and $(41.9 \%$ versus $83.8 \%)$ respectively. The combination of VIA/Pap has better sensitivity and specificity than each independent test ( $82.6 \%$ and $92.2 \%$ ).

Conclusion: The findings of this study showed that VIA has higher sensitivity and lower specificity compared to Pap smear, but a combination of both tests has greater sensitivity and specificity than each test independently. It indicates that VIA is useful for screening of cervical cancer in the primary health care setting in Sudan, but positive results need to be confirmed by colposcopy and biopsy.

Keywords: cervical, cancer, screening, VIA, Pap smear, colposcopy, sensitivity, specificity, predictive value, primary health care setting

\section{Introduction}

Cervical cancer is the third most common cancer in women, and the seventh of overall cancers worldwide, with an estimated 529,000 new cases in the year $2008 .{ }^{1}$ It has been estimated that more than $87 \%$ of the global burden occurs in developing countries, where it accounts for $13 \%$ of all female cancers. High-risk regions include the Eastern and Western Africa regions. ${ }^{1}$ In Sudan cervical cancer ranks as the second most common cancer among women with age-standardized incidence of 15 per 100,000 and age-standardized mortality of 25 per $100,000{ }^{2}$
Correspondence: Ahmed Ibrahim Unit for Health Promotion Research, University of Southern Denmark,

Esbjerg, Denmark

Tel +4565504242

Fax +4565504283

Email aibrahim@health.sdu.dk 
Substantial reduction in cervical cancer will only be realized if sustainable cervical cancer screening programs are implemented on a global scale to assure early detection and treatment of precancerous lesions. Effective programs must meet three targets: at least $70 \%$ of the targeted population should be screened at least once in a lifetime; screening assays and diagnostic tests must be reproducible and sufficiently sensitive; and specificity for the detection of high-grade precursor lesions and effective treatment must be provided. ${ }^{3}$

Screening with use of Pap smear and liquid-based cytology has contributed significantly to the reduction of cervical cancer in developed countries. ${ }^{4}$ In addition, screening for human papillomavirus with use of DNA testing has proven useful in early detection of the disease. ${ }^{5}$ Nevertheless, these methods of screening are very difficult to implement in low-resource countries due to the lack of laboratory infrastructure and trained professionals. Therefore there is a vital need for alternative preventive methods for cervical cancer in developing countries. ${ }^{6}$

Recently, interest in visual inspection with acetic acid (VIA) has increased. Numerous studies have been conducted on its accuracy and its ability to detect cervical lesions when compared with other techniques, both conventional and nonconventional. ${ }^{7}$ VIA has emerged as a promising screening method alternative to cytology based methods. This test is easy, cost-effective, and fits well to low resource countries. ${ }^{8}$ VIA is based on the premise that the majority of preinvasive and invasive cervical lesions are visible on examination by the naked-eye after application of acetic acid. It involves insertion of a vaginal speculum and application of 3\%-5\% acetic acid solution using a cotton swab. After 5 minutes, the cervix is inspected under illumination of a halogen lamp. If there is an acetowhitening area present, the result of the test is positive. The test is negative when there is no acetowhitening area. The normal squamous epithelium tissue of the cervix is pink. On application of acetic acid, cervical intraepithelial neoplasia (CIN) lesion takes on a white color due to the increased precipitation of nuclear proteins and cytokeratins in the cervical epithelium. ${ }^{9}$

This study aimed to determine feasibility of the VIA screening method for cervical cancer as an alternative to a Pap smear in the primary health care setting in Sudan, and to compare performance of VIA and Pap smear.

\section{Materials and methods}

A cross-sectional study of 1250 asymptomatic women living in Khartoum, Sudan, was conducted in primary health care centers in Khartoum State, Sudan, during the period of December 2009 to April 2010. Healthy married women aged 25-50 years, living in Khartoum State and who were willing to participate in screening, were included in the study. Pregnant women, women with absent menstrual periods, and women with a previous history of cervical cancer, abnormal cytology, or hysterectomy, were excluded from the study.

Eligible women were included in the study after they were given information about the study's objectives, screening test procedures, and the benefits to be gained from screening. The women who agreed to participate in the study provided written consent. A questionnaire focusing on sociodemographic, obstetrics and gynecological variables, and other risk factors was filled in by each participant with the assistance of registered nurses. The women then underwent a complete physical and gynecological examination, and pelvic assessment performed by a physician trained in early detection of cancer. The Pap smear sampling and VIA testing were performed by the same physician.

The VIA test was performed by application of 3\%-5\% acetic acid into the cervix uteri by using sterile forceps and a small piece of cotton. After 5 minutes a naked-eye assessment was performed under direct illumination of a 100-watt halogen lamp. A positive VIA test was defined as well-marginated, raised, opaque, acetowhite lesion(s) observed on the cervix uteri within the squamo-columnar junction zone (the region in the uterine cervix in which the squamous lining of the vagina is replaced by the columnar epithelium typical of the body of the uterus and which is a common site of neoplastic change)..$^{10}$

The Pap smear sample was obtained by using a spatula. The Pap smear was fixed with ethanol for 30 minutes and sent to a cytologist for investigation. The cytological results of the Pap smear were reported according to the Bethesda System. ${ }^{10}$ Positive cytology diagnosis was considered when any of these pathological changes were detected: a typical squamous cell of undetermined significance, $\mathrm{CIN}$, or invasive cancer.

Figure 1 demonstrates the flow chart of the study. The total number of women who were invited to participate in the study was 1250 . Of them, 985 women agreed to participate, giving a response rate of $79 \%$. Of the total number of responding women, 51 (5.2\%) were excluded due to varying reasons: 25 had an absence of menstrual periods, 16 were not sure about their last menstrual period, three had a previous history of cervical cancer treatment, and 6 were under fertility treatment.

Women with positive VIA or positive Pap smears were referred to a gynecological oncologist at a specialized 


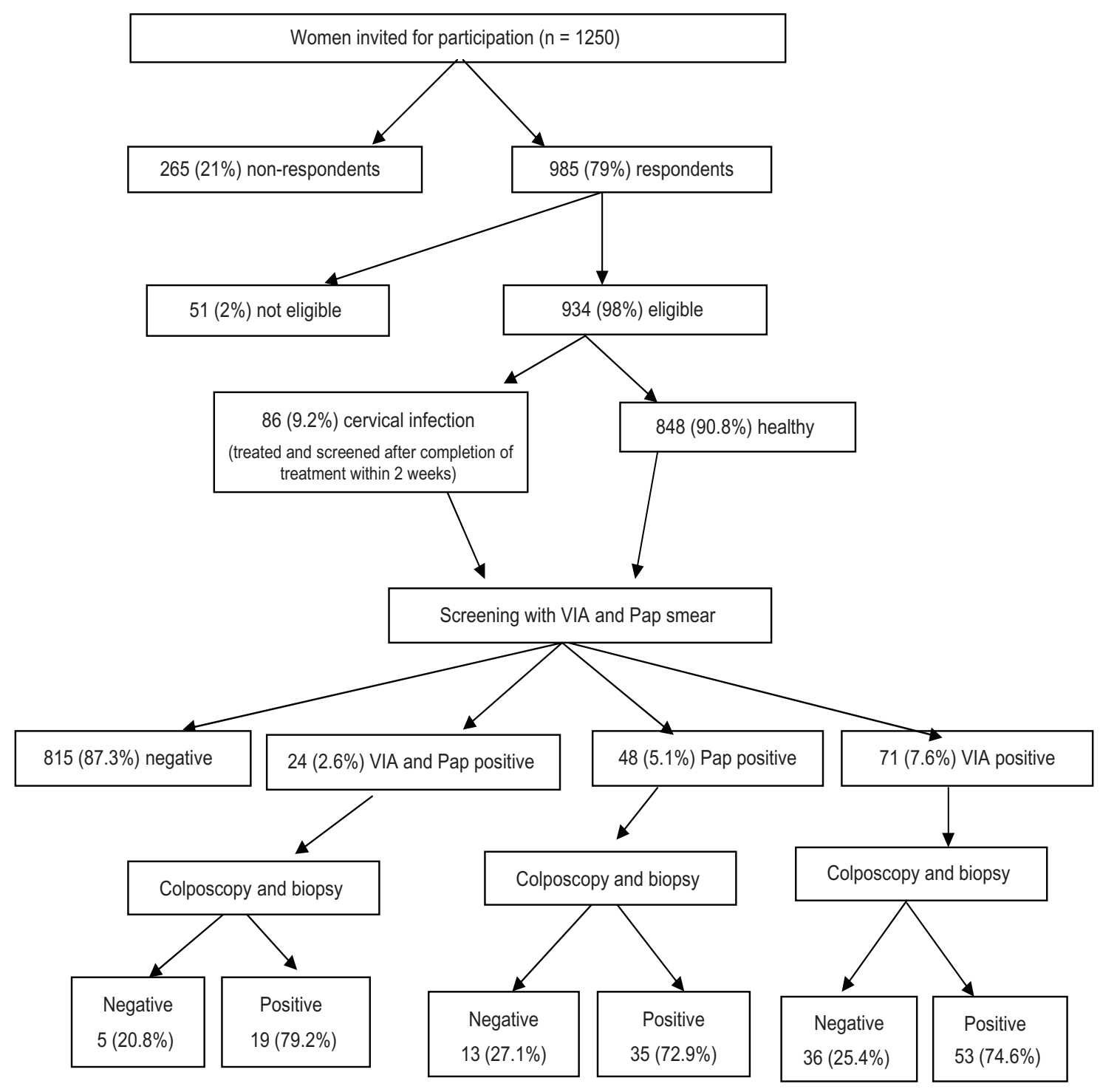

Figure I Flow chart of the study.

Abbreviation: VIA, visual inspection with the use of acetic acid.

oncology center for colposcopy and biopsy. The obtained biopsies were examined by a histopathologist for confirmation of the results of both screening tests. The histopathologist was blinded to the results of the screening tests. The time interval between the screening test and colposcopy was 2-12 days for women with positive VIA and 7-21 days for women with a positive Pap smear; the delay of Pap smear results was due to the laboratory process, which took a longer time to investigate the smear specimens.

\section{Data analysis}

Data were entered into STATA (v9.2; Stata Corp, College Station, TX). Descriptive statistics were used to analyze the demographic data and to compare the results of both screening tests. $t$-tests were used to detect any significant difference between continuous variables (age, age of becoming sexually active, and number of deliveries). The Chi squared test was used to detect any significant difference between categorical variables and positive results of VIA and Pap smear tests in the screened women in each group. Sensitivity, specificity, positive and negative predictive values were compared for both screening tests. $P$ value and $95 \%$ confidence intervals are reported.

\section{Results}

The number of women who fulfilled the eligibility criteria, offered informed consent, and agreed to participate in the study, was 934 (95\% of total number of the respondents).

The mean age of the eligible 934 participants was 34.8 years for those that screened negative and 32.8 years for those 
that screened positive (Table 1). The respective ages of sexual initiation were 20.3 years and 19.8 years. The number of deliveries ranged from one to seven live births, with a mean of two births for the study sample; $35.2 \%$ were nulliparous. The main education level was primary school, and the majority of participating women were principally unpaid domestic workers. The place of residence was urban for $62.1 \%$, and rural for $37.9 \%$ of the women. Almost $90 \%$ of screened women had gone through genital mutilation. The majority of women $(76 \%)$ in the study sample used an oral contraceptive pill, and $76 \%$ of women had an episiotomy during vaginal delivery (Table 1).

All women had undergone counseling and clinical assessment before screening; $86(9.2 \%)$ of them had signs of cervical infection such as chlamydia, bacterial, and Candida albican infections. They received appropriate treatment and were screened 2 weeks after recovering from infection.

The results of all screened women revealed that $71(7.6 \%)$ women were positive when VIA tested, and according to the later Pap smear results 48 (5.1\%) were positive (Table 2). There was an overlap between VIA and Pap smear in positive results of 24 samples.
Comparisons between the study sample characteristics, VIA test positive results, and Pap smear positive results revealed that there was a significant difference in the age of women who tested positive by VIA and Pap smear (mean age 32.3 years versus 38.3 years, respectively). There was a significant difference between positive results of VIA and Pap smear in relation to women who had gone through female genital mutilation $(93.0 \%$ versus $79.2 \%$; $P=0.05)$. There was also a significant difference between women who had cervical infection and positive results of VIA versus Pap smear (33.9\% versus 54.2\%; $P=0.04$; Table 2).

The results of histopathology revealed that 88 of 119 (73.9\%) confirmed positive, of which 53 of 71 (74.6\%) had a positive VIA and $35(72.9 \%)$ had a positive Pap smear. Moreover, classification of the positive specimens showed that $(75 \%)$ of cases were CIN and $(25 \%)$ were in Stage 1. The categories of histopathological findings differed based on the screening test, VIA significantly detected more cases in stage 1 than Pap smears (19 versus 3; $P=0.001$; Table 3 ). There were 24 overlapping positive cases of VIA and Pap

Table I Characteristics of the participants in the screening for cervical cancer by VIA and Pap smear in Khartoum

\begin{tabular}{|c|c|c|c|c|}
\hline \multirow[t]{2}{*}{ Variable } & \multirow{2}{*}{$\begin{array}{l}\text { Total } \\
(n=934)\end{array}$} & \multicolumn{2}{|l|}{ Screening } & \multirow[t]{2}{*}{$P$ value } \\
\hline & & Negative $(n=815)$ & Positive $(n=119)$ & \\
\hline Age, years (mean $\pm S D$ ) & $34.9 \pm 7.6$ & $34.8 \pm 7.6$ & $32.8 \pm 7.6$ & 0.007 \\
\hline Age of sex initiation, years (mean $\pm S D$ ) & $20.1 \pm 2.1$ & $20.3 \pm 2.0$ & $19.8 \pm 1.9$ & 0.01 \\
\hline Number of deliveries (mean $\pm S D$ ) & $1.81 \pm 2.3$ & $1.71 \pm 1.8$ & $1.92 \pm 2.1$ & 0.2 \\
\hline \multicolumn{5}{|l|}{ Education level } \\
\hline No formal education & $247(26.4 \%)$ & $216(26.5 \%)$ & $31(26.0 \%)$ & \multirow[t]{2}{*}{0.01} \\
\hline Basic school & $687(73.6 \%)$ & $599(73.5 \%)$ & $88(74.0 \%)$ & \\
\hline \multicolumn{5}{|l|}{ Employment } \\
\hline Employed & $338(36.2 \%)$ & $286(35.1 \%)$ & $52(43.7 \%)$ & \multirow[t]{2}{*}{0.3} \\
\hline Unemployed & $596(63.8 \%)$ & $529(64.9 \%)$ & $67(56.3 \%)$ & \\
\hline \multicolumn{5}{|l|}{ Residence } \\
\hline Rural & $354(37.9 \%)$ & $314(38.5 \%)$ & $40(33.6 \%)$ & \multirow[t]{2}{*}{0.08} \\
\hline Urban & $580(62.1 \%)$ & $50 \mathrm{I}(6 \mathrm{I} .5 \%)$ & 79 (66.4\%) & \\
\hline \multicolumn{5}{|l|}{ Female genital mutilation } \\
\hline Yes & $836(89.5 \%)$ & $732(89.8 \%)$ & $104(87.4 \%)$ & \multirow[t]{2}{*}{0.5} \\
\hline No & $98(10.4 \%)$ & $83(10.2 \%)$ & $15(12.6 \%)$ & \\
\hline \multicolumn{5}{|l|}{ Contraceptive use } \\
\hline Yes & $710(76.0 \%)$ & $620(76.1 \%)$ & $90(10.4 \%)$ & \multirow[t]{2}{*}{0.9} \\
\hline No & 224 (24.0\%) & 195 (23.9\%) & 29 (3.1\%) & \\
\hline \multicolumn{5}{|l|}{ Delivery type } \\
\hline Nulliparous & $329(35.2 \%)$ & $28 I(34.5 \%)$ & $48(40.3 \%)$ & \multirow[t]{2}{*}{0.2} \\
\hline Parous & $605(64.8 \%)$ & $534(65.5 \%)$ & $71(59.7 \%)$ & \\
\hline \multicolumn{5}{|l|}{ Episiotomy } \\
\hline Yes & $710(76.0 \%)$ & $624(76.6 \%)$ & $86(72.3 \%)$ & \multirow[t]{2}{*}{0.3} \\
\hline No & $224(24.0 \%)$ & 191 (23.4\%) & $33(27.7 \%)$ & \\
\hline \multicolumn{5}{|l|}{ Cervical infection } \\
\hline No infection & $848(90.8 \%)$ & 779 (95.6\%) & $69(58.0 \%)$ & \multirow[t]{2}{*}{0.0001} \\
\hline Infected & $86(9.2 \%)$ & $36(4.4 \%)$ & $50(42.0 \%)$ & \\
\hline
\end{tabular}

Abbreviations: SD, standard deviation; VIA, visual inspection with the use of acetic acid. 
Table 2 Comparison between positive VIA, Pap smear tests, and characteristics of participants in Khartoum $(n=934)$

\begin{tabular}{|c|c|c|c|c|}
\hline \multirow[t]{2}{*}{ Variable category } & \multirow[t]{2}{*}{ All test positive } & \multicolumn{2}{|c|}{ Screening test } & \multirow[t]{2}{*}{$P$ value } \\
\hline & & VIA & Pap smear & \\
\hline Number (\%) of screening positive & $119(12.7 \%)$ & 71 (7.6\%) & $48(5.1 \%)$ & 0.004 \\
\hline Continuous variable & $($ Mean $\pm S D)$ & $($ Mean $\pm S D)$ & $($ Mean $\pm S D)$ & \\
\hline Age, years (mean $\pm S D)$ & $32.8 \pm 7.6$ & $32.3 \pm 6.7$ & $38.3 \pm 6.3$ & 0.0001 \\
\hline Age of sex initiation, years (mean $\pm S D$ ) & $19.8 \pm 1.9$ & $19.8 \pm 1.9$ & $20.3 \pm 2.0$ & 0.1 \\
\hline Number of deliveries (mean $\pm S D$ ) & $1.92 \pm 2.1$ & $1.71 \pm 2$ & $1.92 \pm 2.3$ & 0.5 \\
\hline Categorical variables & n (\%) & n (\%) & n (\%) & \\
\hline \multicolumn{5}{|l|}{ Education level } \\
\hline No formal education & $31(26.0)$ & $19(26.8)$ & $12(25.0)$ & 0.9 \\
\hline Formal education & $88(55.5)$ & $52(54.9)$ & $36(65.3)$ & \\
\hline \multicolumn{5}{|l|}{ Employement } \\
\hline Employed & $52(43.7)$ & $29(40.8)$ & $23(47.9)$ & 0.5 \\
\hline Unemployed & $67(56.3)$ & $42(59.1)$ & $25(52.1)$ & \\
\hline \multicolumn{5}{|l|}{ Residence } \\
\hline Rural & $40(33.6)$ & $23(32.4)$ & $17(35.4)$ & 0.8 \\
\hline Urban & $79(66.4)$ & $48(67.6)$ & $31(64.6)$ & \\
\hline \multicolumn{5}{|l|}{ Female genital mutilation } \\
\hline Yes & $104(87.4)$ & $66(93.0)$ & $38(79.2)$ & 0.05 \\
\hline No & $15(12.6)$ & $5(7.0)$ & $10(20.8)$ & \\
\hline \multicolumn{5}{|l|}{ Contraceptive use } \\
\hline Yes & $90(10.4)$ & $55(77.5)$ & $35(72.9)$ & 0.08 \\
\hline No & $29(3.1)$ & $16(22.5)$ & I3 (27.I) & \\
\hline \multicolumn{5}{|l|}{ Delivery type } \\
\hline Nulliparous & $46(38.7)$ & $30(42.3)$ & $16(33.3)$ & 0.9 \\
\hline Parous & $73(59.7)$ & $4 \mathrm{I}(57.7)$ & $32(66.7)$ & \\
\hline \multicolumn{5}{|l|}{ Episiotomy } \\
\hline Yes & $86(72.3)$ & 55 (77.5) & $31(64.6)$ & 0.8 \\
\hline No & $33(27.7)$ & $16(22.5)$ & $17(35.4)$ & \\
\hline \multicolumn{5}{|l|}{ Cervical infection } \\
\hline No infection & $69(58.0)$ & $47(66.1)$ & $22(45.8)$ & 0.04 \\
\hline Infected & $50(42.0)$ & $24(33.9)$ & $26(54.2)$ & \\
\hline
\end{tabular}

Abbreviations: SD, standard deviation; VIA, visual inspection with the use of acetic acid.

smear, of which $52.6 \%, 31.6 \%, 10.5 \%$, and $5.3 \%$ were CIN1, CIN2, CIN3, and stage 1, respectively.

Comparison of the performance of two VIA and Pap smears in terms of sensitivity and specificity, and in positive and negative predictive values brought varied results (Table 4). VIA had higher sensitivity than Pap smear but lower specificity. VIA/Pap combined had higher sensitivity and specificity than VIA and Pap smear alone.

\section{Discussion}

African countries rank second highest for morbidity and mortality of cervical cancer after Asia. ${ }^{1}$ Sudan occupies the top level of cervical cancer morbidity and mortality in northern African countries. ${ }^{2}$ In these countries there are no screening programs, or the programs are ineffectively developed and poorly organized. The majority of the screening programs are using the Pap smear method and attempt to imitate the excellent outcome achieved in developed countries (Finland is the best worldwide example for decrease in cervical cancer incidence as a result of a well-organized screening program). ${ }^{27}$ Nevertheless, the results of these programs have been very poor due to lack of infrastructure, inadequate training for medical staff, poor organization, lower coverage of women at risk, no standardized quality control systems, and a lack of follow-up and treatment of positive cases. ${ }^{12}$ Therefore, in recent years, screening using a new method has emerged as an alternative to the conventional Pap smear, which involves visual inspection with use of acetic acid. ${ }^{7}$

VIA has become a promising alternative for developing countries because it is inexpensive, rapid, requires brief training, and does not require laboratory equipment. A number of earlier studies have reported that VIA has a comparable or superior result to Pap smears in the detection of cervical cancer. ${ }^{8}$

This is the first study carried out to determine the feasibility of VIA as a screening method for cervical cancer in the primary health care setting in Sudan. The study 
Table 3 Comparison between VIA and Pap positive total women $(n=119)$ undergone colposcopy and histopathology

\begin{tabular}{|c|c|c|c|c|c|}
\hline & Total (\%) & $\begin{array}{l}\text { VIA test } \\
\text { n (\%) }\end{array}$ & $\begin{array}{l}\text { Pap smear } \\
\mathrm{n}(\%)\end{array}$ & $P$ value & $\begin{array}{l}\text { Overlap both VIA } \\
\text { and Pap positive (\%) }\end{array}$ \\
\hline Total screened positive & 119 & 7I (7.5) & $48(5.1)$ & 0.004 & $24(20.2)$ \\
\hline $\begin{array}{l}\text { Total confirmed by } \\
\text { colposcopy and biopsy }\end{array}$ & $88(73.9)$ & $53(74.6)$ & 35 (72.9) & 0.05 & $19(79.2)$ \\
\hline \multicolumn{6}{|c|}{ Classification of confirmed positive } \\
\hline $\mathrm{CINI}$ & $12(13.6)$ & $4(7.5)$ & $8(22.9)$ & $0.2^{*}$ & $10(52.6)$ \\
\hline CIN2 & $26(29.5)$ & $14(26.4)$ & $12(34.3)$ & 0.7 & $6(31.6)$ \\
\hline CIN3 & $28(31.8)$ & $16(30.2)$ & $12(34.2)$ & 0.4 & $2(10.5)$ \\
\hline Stage I & $22(25.0)$ & $19(35.8)$ & $3(8.6)$ & $0.00 I^{*}$ & I (5.3) \\
\hline
\end{tabular}

Note: *Yates Chi-square test and $P$ value.

Abbreviations: $\mathrm{CIN}$, cervical intraepithelial neoplasia; VIA, visual inspection with the use of acetic acid.

was preceded by a pilot study which showed that $16 \%$ of screened women were positive when screened by VIA. ${ }^{13}$ The result of the final study is lower (7.6\%). This difference could be due to sampling variation and the selected study population criteria. The findings of this study revealed that VIA detected significantly more positive women than Pap smears ( $7.6 \%$ versus $5.1 \% ; P=0.004)$ with an overlap between the two screening tests in $19 \%$ of positive results. VIA had higher sensitivity and positive predictive values than Pap smears but lower specificity and negative predictive values, respectively. VIA detected more confirmed diagnosed cases of intraepithelial cervical intraepithelial neoplasia than Pap smears; however, the difference was not statistically significant and in the confirmed diagnosed cases of invasive cervical cancer in stage 1, VIA detected significantly more cases than Pap smears $(35.8 \%$ versus $8.6 \% ; P=0.001$ ).

The result of screened-positive women by VIA in this study $(7.6 \%)$ was higher than that found in Bangladesh $(4.8 \%)^{14}$ and in Angola (6.6\%), ${ }^{15}$ but lower than in Kenya $(13.9 \%)^{16}$ or in Honduras $(14 \%),{ }^{17}$ and it was much lower than found in El Salvador $(26.5 \%),{ }^{18}$ or in Thailand $(38.1 \%) .{ }^{19}$

In our study the sensitivity of VIA was $60.2 \%$. This finding is similar to that reported in Tanzania $(60.6 \%),{ }^{20}$ higher than in Colombia (53.6\%), ${ }^{21}$ but lower than in India $(80.0 \%),{ }^{22}$ in Angola (70.7\%), ${ }^{15}$ and, again, in India (98\%). ${ }^{23}$
Sensitivity and specificity of the VIA test in this study was consistent with pooled VIA sensitivity that was described by an International Agency on Research for Cancer multicenter study in India and Africa. ${ }^{24}$ The specificity of the VIA test in our study was $42 \%$; it was lower compared to Pap smears $(65 \%)$, and lower than found for VIA in Kenya $(75 \%)^{25}$ and in Angola (94.5\%). ${ }^{15}$

There was only a small (although marginally significant, $P=0.05)$ difference in the total proportion of confirmed cases by colposcopy (74.6\% versus $72.9 \%$ ) for VIA and Pap respectively. There was no significant difference in confirmed cases of CIN1, CIN2, and CIN3 among the VIA positive tests than among the Pap positive tests. In turn, VIA detected significantly more $(P<0.001)$ cases of cervical cancer in stage $1(35.8 \%)$ than Pap smears (8.6\%). The sensitivity value for VIA in our study is higher than that found by Basu et al in Calcutta, India; $74.6 \%$ and $55.7 \%$ respectively. ${ }^{26}$ In our study VIA detected more cases of CIN than Pap smear (36 versus 32). Nevertheless, the results of this study delineate the potential benefits of using VIA within the primary health care setting in low resource countries. VIA increases detection of premalignant lesions of the cervix and diminishes the probability of women defaulting before they are appropriately followed-up and treated. We believe that VIA can be used as a screening tool in low resource countries, not only in the primary health care setting but also in general hospitals.

Table 4 Comparison of VIA and Pap smear tests performance in Khartoum (934 women)

\begin{tabular}{lllllll}
\hline & VIA test & $\mathbf{9 5 \%} \mathbf{C l}$ & Pap smear & $\mathbf{9 5 \%} \mathbf{C l}$ & VIA/Pap & $\mathbf{9 5 \%} \mathbf{C l}$ \\
\hline Sensitivity & 60.2 & $49.8-69.8$ & 47.7 & $37.5-58.0$ & 82.6 & $63.9-93.0$ \\
Specificity & 41.9 & $26.4-59.2$ & 83.8 & $68.9-92.3$ & 92.2 & $83.0-96.6$ \\
Positive predictive value & 74.6 & $63.3-83.3$ & 87.5 & $75.3-94.1$ & 79.2 & $59.5-90.8$ \\
Negative predictive value & 27.1 & $16.6-41.0$ & 40.3 & $30.0-51.4$ & 93.7 & $84.8-97.5$ \\
\hline
\end{tabular}

Abbreviations: $\mathrm{Cl}$, confidence interval; $\mathrm{VIA}$, visual inspection with the use of acetic acid. 


\section{Conclusion}

The results of this study showed that VIA has higher sensitivity, but lower specificity, compared to Pap smears. A combination of VIA/Pap increased sensitivity and specificity of detection of cervical cancer. The findings of the study indicate that VIA is useful for the screening of cervical cancer in the primary health care setting in Khartoum State, Sudan.

\section{Disclosure}

The authors report no conflicts of interest in this work.

\section{References}

1. Ferlay J, Shin H, Bray F, Forman D, Mathers C, Parkin DM. Estimates of worldwide burden of cancer in 2008. Int J Cancer. 2010;127: 2893-2917.

2. GLOBOCAN. Cancer Incidence and Mortality Worldwide in 2008. International Agency on Research for Cancer. Available from: http:// globocan.iarc.fr/. Accessed December 23, 2011.

3. Gravitt PE, Belinson JL, Salmeron J, Shah KV. Looking ahead: a case for human papillomavirus testing of self-sampled vaginal specimens as a cervical cancer screening strategy. Int J Cancer. 2011; 129(3):517-527.

4. Duraisamy K, Jaganathan KS, Bose JC. Methods of detecting cervical cancer. Adv Bio Res. 2011;5(4):226-232.

5. Nelson R. HPV testing most successful in cervical cancer developing countries. N Engl J Med. 2009;360(14):1385-1394.

6. Gaikwad NL, Mahajan NN, Mahajan KN. Re: Alternative cervical cancer prevention in low-resource settings: experiences of visual inspection by acetic acid with single-visit approach in the first five provinces of Thailand. Aust N Z J Obstet Gynaecol. 2007;47(3):258-259.

7. Gaffikin L, Lauterbach M, Blumenthal PD. Performance of visual inspection with acetic acid for cervical cancer screening: a qualitative summary of evidence to date. Obstet Gynecol Surv. 2003;58(8):543-550.

8. Sarian LO, Derchain SF, Naud P, et al. Evaluation of visual inspection with acetic acid (VIA), Lugol's iodine (VILI), cervical cancer cytology and HPV testing screening tools in Latin America. This report refers to partial results from the LAMS (Latin American Screening) study. J Med Screen. 2005;12(3):142-149.

9. Carr KC, Sellem MW. Cervical cancer screening in low resource setting using visual inspection with acetic acid. J Midwifery Womens Health. 2004;49(4):329-337.

10. Sankaranarayanan MD, Ramani S, Wesley MD. Testing and reporting the results of visual inspection with $5 \%$ acetic acid (VIA). In: IARC Screening Group, editors. A Practical Manual on Visual Screening for Cervical Neoplasia. Lyon, France: IARC; 2003:15-28.

11. Solomon D, Davey D, Kurman R, et al. The 2001 Bethesda System: terminology for reporting results of cervical cytology. JAMA. 2002; 287(16):2114-2119.

12. Jeronimo J, Morales $\mathrm{O}$, Horna J, et al. Visual inspection with acetic acid for cervical cancer screening outside of low-resource settings. Rev Panam Salud Publica. 2005;17(1):1-5.
13. Ibrahim A, Rasch V, Pukkala E, Aro AR. Cervical cancer, risk factors and feasibility of acetic acid screening method in Sudan. Int J Womens Health. 2011;3:117-121.

14. Nessa A, Hussain MA, Rahman JN, Rashid MH, Muwonge R, Sankaranarayanan R. Screening for cervical neoplasia in Bangladesh using visual inspection with acetic acid. Int J Gynaecol Obstet. 2010; 111(2):115-118

15. Muwonge R, Manuel Mda G, Filipe AP, Dumas JB, Frank MR, Sankaranarayanan R. Visual screening for early detection of cervical neoplasia in Angola. Int J Gynaecol Obstet. 2010;111(1):68-72.

16. Were E, Nyaberi Z, Buziba N. Integrating cervical cancer and genital tract infection screening into mother, child health and family planning clinics in Eldoret, Kenya. Afr Health Sci. 2010;10(1):58-65.

17. Perkins RB, Langrish SM, Stern LJ, Figueroa J, Simon CJ. Comparison of visual inspection and Papanicolau (PAP) smears for cervical cancer screening in Honduras: should PAP smears be abandoned? Trop Med Int Health. 2007;12(9):1018-1025.

18. Cremer M, Bullard K, Maza M, et al. Cytology versus visual inspection with acetic acid among women treated previously with cryotherapy in a low-resource setting. Int J Gynaecol Obstet. 2010;111(3):249-252.

19. Ekalaksananan T, Pientong C, Thinkhamrop J, Kongyingyoes B, Evans MF, Chaiwongkot A. Cervical cancer screening in north east Thailand using the visual inspection with acetic acid (VIA) test and its relationship to high-risk human papillomavirus (HR-HPV) status. J Obstet Gynaecol Res. 2010;36(5):1037-1043.

20. Ngoma T, Muwonge R, Mwaiselage J, Kawegere J, Bukori P, Sankaranarayanan R. Evaluation of cervical visual inspection screening in Dar es Salaam, Tanzania. Int J Gynaecol Obstet. 2010;109(2): 100-104.

21. Murillo R, Luna J, Gamboa O, Osorio E, Bonilla J, Cendales R; INC Cervical Cancer Screening Study Group. Cervical cancer screening with naked-eye visual inspection in Colombia. Int J Gynaecol Obstet. 2010;109(3):230-234.

22. Sahasrabuddhe VV, Bhosale RA, Kavatkar AN, et al. Comparison of visual inspection with acetic acid and cervical cytology to detect high-grade cervical neoplasia among HIV-infected women in India. Int J Cancer. 2011;130(1):234-240.

23. Aggarwal P, Batra S, Gandhi G, Zutshi V. Comparison of Papanicolaou test with visual detection tests in screening for cervical cancer and developing the optimal strategy for low resource settings. Int J Gynecol Cancer. 2010;20(5):862-868.

24. Sankaranarayanan R, Basu P, Wesley RS, et al; IARC Multicentre Study Group on Cervical Cancer Early Detection. Accuracy of visual screening for cervical neoplasia: Results from an IARC multicentre study in India and Africa. Int J Cancer. 2004;110(6):907-913.

25. Mutyaba T, Mirembe F, Sandin S, Weiderpass E. Evaluation of 'seesee and treat' strategy and role of HIV on cervical cancer prevention in Uganda. Reprod Health. 2010;7:4.

26. Basu PS, Sankaranarayanan R, Mandal R, et al; Calcutta Cervical Cancer Early Detection Group. Visual inspection with acetic acid and cytology in the early detection of cervical neoplasia in Kolkata, India. Int J Gynecol Cancer. 2003;13(5):626-632.

27. Aareleid T, Pukkala E, Thomson H, Hakama M. Cervical cancer incidence and mortality trends in Finland and Estonia: a screened vs. an unscreened population. Eur J Cancer. 1993;29A(5):745-749.
International Journal of Women's Health

\section{Publish your work in this journal}

The International Journal of Women's Health is an international, peerreviewed open-access journal publishing original research, reports, reviews and commentaries on all aspects of women's healthcare including gynecology, obstetrics, and breast cancer. Subject areas include: Chronic conditions (migraine headaches, arthritis, osteoporosis);

\section{Dovepress}

Endocrine and autoimmune syndromes; Sexual and reproductive health; Psychological and psychosocial conditions. The manuscript management system is completely online and includes a very quick and fair peer-review system. Visit http://www.dovepress.com/ testimonials.php to read real quotes from published authors. 